\title{
Fuzzy Comprehensive Evaluation Method-based Big Data Era Chinese Sports Brands Independent Innovation Ability Research
}

\author{
Shujun $\mathrm{Ma}^{*}$ \\ Institute of Physical Education, Pingdingshan University, Pingdingshan 467000, Henan, China
}

\begin{abstract}
With the rapid development of economy, use of sports products in people's daily life has greatly increased. However, the status of China's native sports products' sales has not improved considerably. Generally, most of the people select internationally famous brands, thereby reducing the sales of China's native sports brands. Chinese sports brands have been facing challenges due to international brands ; thus making their independent innovation reformation imperative. The paper utilized fuzzy comprehensive evaluation method to evaluate brands' independent innovation ability from China's sports brands, their market share, loyalty index, and the domestic leadership. Regarding the world famous brandNike, for the independent innovation distribution status as evaluation weight, the obtained result shows ERKE 361 degree. XTEP is the sports brand of higher independent innovation abilities, which are worthier than the other brands.
\end{abstract}

Keywords: Big data, Fuzzy comprehensive evaluation method, Independent innovation, Sports brands, Model establishments, Brand value.

\section{INTRODUCTION}

With the advent of economic globalization, all kinds of Chinese products have been exported abroad. However, the market share of Chinese sports products in the international level is still lower, which is less than one percentage of the market share of internationally famous sports brands. China has gradually moved towards world powers, and people hope that more "made in China" products can be revised as "created in China". Such essential transformation of the economic industry cannot be made possible without independent innovation [1].

Fang Wei in the article "Chinese traditional national sports brands independent innovation research", selected the traditional national sports brands as research objects, and with multiple research methods, analysed problems in the development of traditional Chinese sports brands and put forward reasonable suggestions. The article pointed out that the share of these national traditional sports brands in the international market was smaller, due to ineffective planning of programs, improper advertising, and lack of intracompany operating management professionals [2]. The author pointed out that for the development of Chinese traditional national sports brands, China needs to adopt brand independent innovation as the mainline strategy to strengthen competitive innovation and other multiple aspects' innovation [3].

Feng Bao-Zhong in the article "Research on China marching towards sports powers paths", pointed out that China has gradually moved toward world sports powers, as a result of the progress in sports, sports industries and other multiple aspects.

\footnotetext{
*Address correspondence to this author at the Institute of Physical Education, Pingdingshan University, Pingdingshan 467000, Henan, China; Tel: +086-13938670939; E-mail: shujunx@sina.com
}

Chinese sports industries should set the development target, main tasks and development layout under the guidance of "sports powers" target. This should implement regional sports "branding" strategy, based on the target of sports powers, and carry out standardized processing with regional sports products recognition and their advertisement [4]. Xie Qiang in "Chinese sports product brands development status research", used multiple research methods, combined with the world's multiple sports brands, examined the status of China's sports products development and the existing advantages. He made comparison between world's famous sports brands such as Nike's development history with China's sports brands development, explaining existing problems in the Chinese sports products, such as low scientific and technological contents, incorrect brand positioning, lacking of professionals, large gap between strategic planning and concrete execution, lacking of brands cultures and so on. The author pointed out that China's sports products should include high-end, middle-end and low-end products, set up brand consciousness, focus on global competitions, participate in the international brands competitions, and employ all kinds of professional experts. Li Liang in the article "China sports industry brands development comparative analysis", pointed out that sports industry is the tertiary industry that directly propels the growth of national economy growth. Since China succeeded in hosting Olympic Games in 2008, sports industry has rapidly developed. China's national traditional sports brands became immaterial assets. Compared to the internationally famous brands, its market competitiveness and enterprise culture power have certain gaps. To promote Chinese gross value of production, social consumption level and import and export trade orders, the author put forward relative policies and suggestions. The author started examining from the perspective of sports brands connotations, researched on relative totality data and component data 
Table 1. 2006 world 500 most valuable brands status table.

\begin{tabular}{|c|c|c|c|c|c|}
\hline Brand Name & Impact & Market Share & Loyalty Index & Global Leadership & Brand Value (Global) \\
\hline \hline Nike & 5 & 4 & 5 & 5 & 101 hundred million dollars \\
\hline Adidas & 4 & 4 & 4 & 5 & 45 hundred million dollars \\
\hline Puma & 2 & 2 & 2 & 2 & 6.74 hundred million dollars \\
\hline
\end{tabular}

Table 2. World brands status table after normalization.

\begin{tabular}{|c|c|c|c|c|}
\hline Brand name & Impact & Market Share & Loyalty Index & Global Leadership \\
\hline \hline Nike & 0.26 & 0.22 & 0.26 & 0.26 \\
\hline Adidas & 0.24 & 0.24 & 0.24 & 0.28 \\
\hline Puma & 0.25 & 0.25 & 0.25 & 0.25 \\
\hline
\end{tabular}

Table 3. 2006 China 500 most valuable brands status table.

\begin{tabular}{|c|c|c|c|c|}
\hline Brand name & Impact & Market Share & Loyalty Index & Domestic Leadership \\
\hline \hline ERKE & 4 & 4 & 3 & 3 \\
\hline 361 degree & 3 & 2 & 3 & 3 \\
\hline XTEP & 2 & 2 & 2 & 2 \\
\hline Deerway & 2 & 2 & 2 & 2 \\
\hline Jinak & 2 & 2 & 3 \\
\hline
\end{tabular}

relations, highlighted the advantages of competition and provided suggestions [5].

The paper aims to study China sports independent innovation level in big data era background, pursuing sports brands independent innovation representative factors and taking them as research evidence.

\section{MODEL ESTABLISHMENTS}

Sports brands independent innovation involves multiple aspects such as, technological innovation of products, innovation in the management of operating mode, product position strategic innovation and so on. However, by analyzing independent innovation, we can consider brands' impacts, market share, loyalty index and domestic leadership. Therefore, we regarded impacts, market share, loyalty index and domestic leadership as evidence to judge independent innovation ability.

\subsection{Data Collecting and Processing}

Tables 1-3 show the data of the world brands research institute and China brands research institute. In the Table, 1-5 represent scores status ( 1 is the lowest score; 5 is the highest score).

From Table 1, it can clearly be seen that Nike is the most famous sports brand with the highest brand value. Adidas ranks the second, with Puma being the third famous brand.
Based on Table 1 showing the impacts, market share, loyalty index, global leadership normalization process was carried out to obtain Table 2.

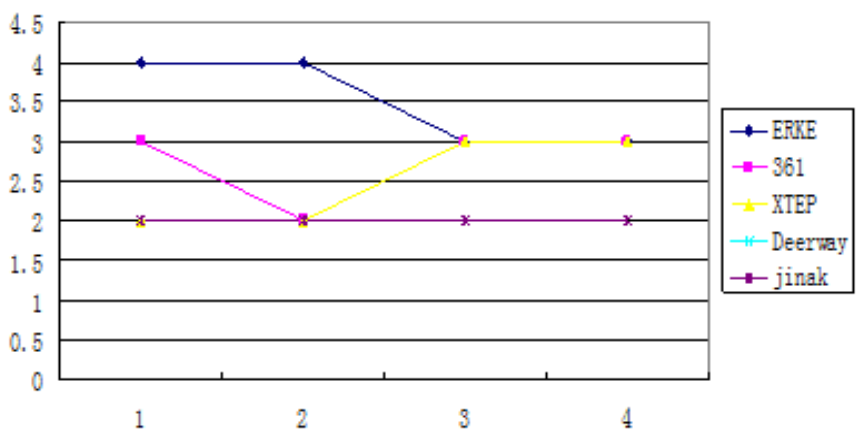

Fig. (1). Chinese sports brand case diagram.

Table 3 shows the results of preliminary comparison; shown as broken line figure in Fig. (1). From Fig. (1), we can see that the statuses of Jinak and Deerway were the same.

Table 2 shows five Chinese native sports brands along with their market share in internationally, which was lower and almost equal to zero. Chinese Lining only occupies one percent share in the international market, but it was not included. Based on the data presented in Table 2, normalization process was carried out, the results of which are shown in Table 4. 
Table 4. China brands status table after normalization.

\begin{tabular}{|c|c|c|c|c|}
\hline Brand Name & Impact & Market Share & Loyalty Index & Domestic Leadership \\
\hline \hline ERKE & 0.29 & 0.29 & 0.21 & 0.21 \\
\hline 361degree & 0.27 & 0.19 & 0.27 & 0.27 \\
\hline XTEP & 0.2 & 0.2 & 0.3 & 0.3 \\
\hline Deerway & 0.25 & 0.25 & 0.25 & 0.25 \\
\hline Jinak & 0.25 & 0.25 & 0.25 & 0.25 \\
\hline
\end{tabular}

\subsection{Fuzzy Comprehensive Evaluation}

In general, fuzzy comprehensive evaluation involves three quantities. It was assumed that there are $n$ evaluated objects with correlation factors shown as $U=\left\{u_{1}, u_{2}, \cdots, u_{n}\right\}$, which is a factor set, with $m$ pieces, $V=\left\{v_{1}, v_{2}, \cdots, v_{m}\right\}$, which is known as an evaluation set. As every factor position is different, its function is also different. Showing measurement criterion as weight, and $A=\left\{a_{1}, a_{2}, \cdots, a_{n}\right\}$.

Comprehensive evaluation steps with fuzzy comprehensive evaluation steps are as follows:

(1) Define factor set as $U=\left\{u_{1}, u_{2}, \cdots, u_{n}\right\}$.

(2) Define evaluation set as $V=\left\{v_{1}, v_{2}, \cdots, v_{m}\right\}$.

(3) Carry out single factor evaluation and obtain $r_{i}=\left\{v_{i 1}, v_{i 2}, \cdots, v_{i m}\right\}$.

(4) Construct an comprehensive evaluation matrix:

$$
R=\left[\begin{array}{cccc}
r_{11} & r_{12} & \cdots & r_{1 m} \\
r_{21} & r_{22} & \cdots & r_{2 m} \\
\vdots & \vdots & & \vdots \\
r_{n 1} & r_{n 2} & \cdots & r_{n m}
\end{array}\right]
$$

(5) Carrying out comprehensive evaluation to determine weight $A=\left\{a_{1}, a_{2}, \cdots, a_{n}\right\}$, calculate $B=A \circ R$, and make evaluation according to the maximum membership principle.

For comprehensive evaluation, there are different models according to different definitions of the operator $\mathrm{O}$.

(1) Modell: $M(\wedge, \vee)$ - Principal divisor decisive type

Computing method is as follows:

$b_{j}=\max \left\{\left(a_{i} \wedge r_{i j}\right), i=1,2, \cdots, n\right\}(j=1,2, \cdots, m)$

The model evaluation result highlighted the main factors that have significant effects on total evaluation, and other factors which did not affect the impact on evaluation. Relatively, the model is fit for the case in which comprehensive evaluation is thought to be optimal when single evaluation is optimal.

(2) Model II: $M(\bullet, \vee)$ - Principal divisor prominent type
Computing method is:

$b_{j}=\max \left\{\left(a_{i} \bullet r_{i j}\right), i=1,2, \cdots, n\right\}(j=1,2, \cdots, m)$

The model has some similarities withl model I, but it is more refined than model I. It not only highlighted the main factors, but also gave considerations to other factors. The model is fit for the range that model $\mathrm{I}$ is inapplicable, and when each factor cannot be distinguished but is needed to be refined.

(3) Model III: $M(\bullet,+)$ - Weighted average type

Computing method is:

$b_{j}=\sum_{i=1}^{n} a_{i} \bullet r_{i j}(j=1,2, \cdots, m)$

The model based on the importance of each factor considered all the influence factors, which is relatively fit for the case that requires comprehensive optimization.

(4) Model IV: $M(\wedge, \oplus)$ - Taking sum of small upper bound type, the

computing method is:

$b_{j}=\min \left\{\left(1, \sum_{i=1}^{n}\left(a_{i} \wedge r_{i j}\right)\right)\right\}(j=1,2, \cdots, m)$

In the model,: every $a_{i}$ cannot take excessively larger value, otherwise $b_{j}$ will be 1 ; similarly every $a_{i}$ cannot take excessively smaller value, otherwise $b_{j}$ will be equal to the sum of each $a_{i}$, which will lead to the loss of the information of single factor evaluation .

(5) ModelV: $M(\wedge,+)$ - Balanced average type

Computing method is:

$b_{j}=\sum_{i=1}^{n}\left(a_{i} \wedge \frac{r_{i j}}{r_{0}}\right)(j=1,2, \cdots, m)$

Among them, $r_{0}=\sum_{k=1}^{n} r_{k j}$. The model is fit for comprehensive evaluation matrix $R$ with both larger and smaller elements. 
The paper established the model using principal divisor decisive type operator. By considering five sports brands (ERKE 、361 degree、XTEP、Deerway、Jinak), the method highlighted the problem in the evaluation of independent innovation and highlighted independent innovation levels of different sports brands. Therefore, the paper established factor set $U=\left\{u_{1}, u_{2}, u_{3}, u_{4}\right\}$, in which $u_{1}$ represents sports brand impacts, $u_{2}$ represents sports brands market share, $u_{3}$ represents sports brands loyalty index, and $u_{4}$ represents sports brands domestic leadership. In the following graph, mark number "1" represents impacts, " 2 " represents market share, " 3 " represents loyalty index and " 4 " represents domestic leadership of the sports brands.

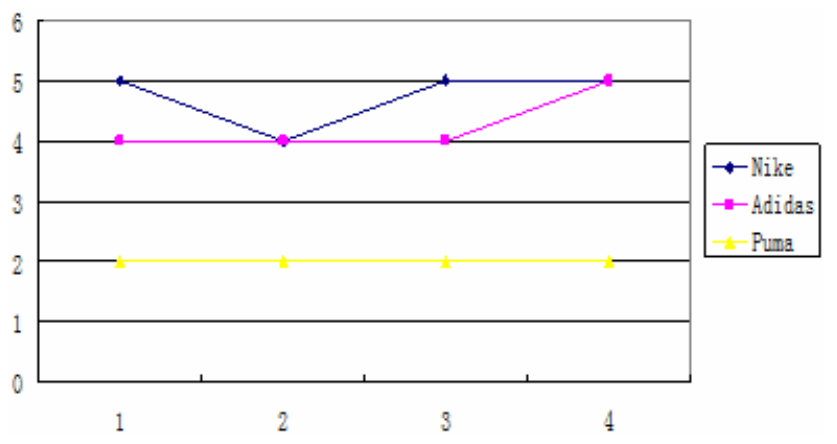

Fig. (2). International sports brand case diagram.

The model selected two brands as weights from Nike, Adidas and Puma. From Fig. (2), it is clear that the statuses of Nike and Adidas were relatively similar. Puma had a different status from the two, so we selected Nike and Puma as weights.

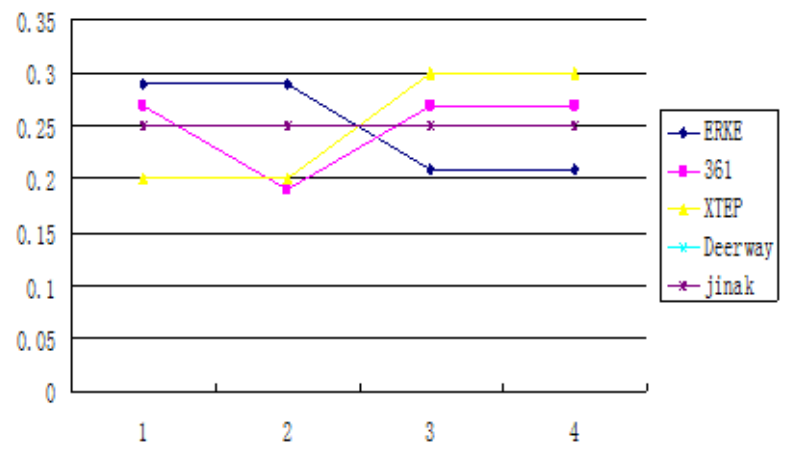

Fig. (3). The normalized data line chart.
Fig. (3) shows the broken line graph of China's sports brands after normalization. Fig. (3), shows the impacts, market share, loyalty index and domestic leadership of five kinds of China's native sports brands after normalization. The figure only reflects the distribution status but cannot reflect independent innovation ability level, therefore, following calculation was carried out.

Table 2 shows two kinds of weights, weight $A_{1}$ that selected Nike sports brand as an example, weight $A_{2}$ that took Puma sports brand as an example, they are represented as:

$$
\begin{aligned}
& A_{1}=(0.26,0.22,0.26,0.26) \\
& A_{2}=(0.25,0.25,0.25,0.25)
\end{aligned}
$$

The data of Table 4 was used to establish comprehensive evaluation matrix $R$ :

$$
R=\left[\begin{array}{lllll}
0.29 & 0.27 & 0.2 & 0.25 & 0.25 \\
0.29 & 0.19 & 0.2 & 0.25 & 0.25 \\
0.21 & 0.27 & 0.3 & 0.25 & 0.25 \\
0.21 & 0.27 & 0.3 & 0.25 & 0.25
\end{array}\right]
$$

Model $M(\wedge, \vee)$ was taken as the evident to calculate two weights to obtain :

$$
\begin{aligned}
& B_{1}=A_{1} \circ R=(0.26,0.26,0.26,0.25,0.25) \\
& B_{2}=A_{2} \circ R=(0.25,0.25,0.25,0.25,0.25)
\end{aligned}
$$

In order to clearly display evaluation results, the comparison between the results of Nike and Puma as weights are shown in the graph in Fig. (4).

\subsection{Analyze Results}

From the above results, it can be observed that with different weights of different sports brands, independent innovation abilities were different. Below are the results of the analyses of two kinds of different weights.

When using weights that took Nike as an example, the weights of impacts, loyalty index, and domestic leadership were relatively larger. ERKE, 361 degree and XTEP, were the independent innovation level of three sports brands. Deerway andJinak had low independent innovation levels. The paper conducted the analysis on two aspects. On, one hand, due to ERKE、 361 degree, and XTEP, the three brands advertising innovation levels are higher. On the other hand,

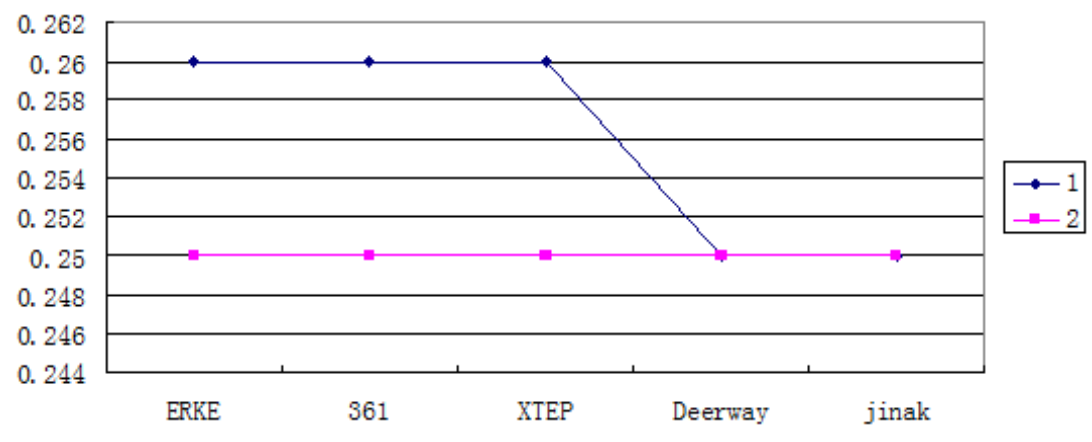

Fig. (4). Two results comparison chart. 


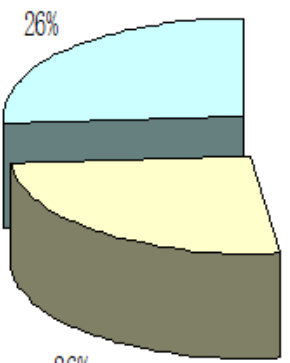

$26 \%$
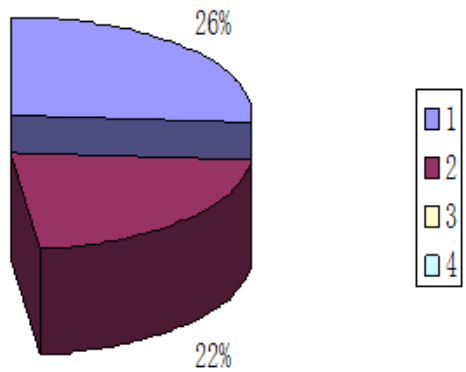

Fig. (5). Nike weight chart
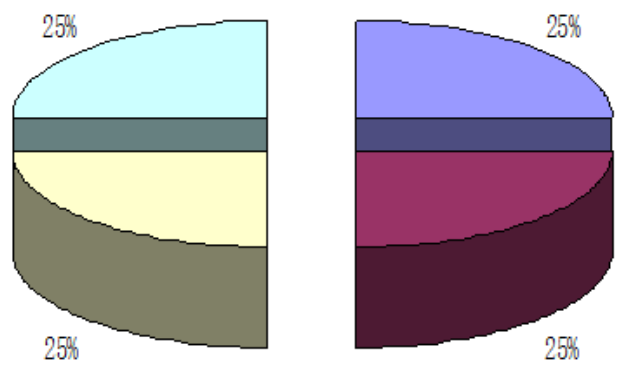

Fig. (6). Puma weight chart.

the three brand's sports products strength in terms of technological innovation is higher.

When using weights that take Puma as an example, the proportion of impacts, market share, loyalty index and domestic leadership were the same. The evaluation result showed that ERKE, 361 degree, XTEP, Deerway and Jinak had the same independent innovation abilities. The result does not conform to the practical life's problems, therefore weight that took Puma as an example, did not conform to the evaluation principles.

As to the purpose of the research was to evaluate China sports brands independent innovation ability, the evaluation result showed China sports products as independent innovation evidence. With respect to foreign sports brands, China excellent independent innovation brands have more practical reference basis. To sum up, when measuring China sports brands independent innovation ability, weight results with Nike as an example are more reasonable. Nike weight is as shown in Fig. (5). Chinese sports products companies such as ERKE 、361 degree, XTEP and others have shown stronger independent innovation abilities.
The paper established models and examined the problems in the international sports brands independent innovation abilities.

\section{CONCLUSION}

The paper used fuzzy comprehensive evaluation method for the analyses. The key to the whole process is establishing the fuzzy comprehensive evaluation matrix. The matrix was formed based on the evaluation results of a single element. Readers can give weights by themselves according to experiences or by referring to other documents data. But once the weight is unreasonable, it will lead to wrong computing process and affect the rationality of results.

The model obtained result showed that ERKE, 361 degree and XTEP are the sports brands with stronger independent innovation abilities. China's sports brands are mostly the followers of internationally famous brands rather than world's sports products leaders. Therefore, Chinese sports brands not only need innovation in advertising, marketing programs and other aspects, but also in the product design concepts and texture selection . .

\section{CONFLICT OF INTEREST}

The author confirms that this article content has no conflict of interest.

\section{ACKNOWLEDGEMENTS}

Declared none.

\section{REFERENCES}

[1] D. Feng, W. Xiang-zhi, and Z. Lin, "Preliminary study on enforcement process and effects of china's policy about sports service industry," J. Nanjing Inst. Phys. Educ., vol. 26, no. 1, pp. 35-41, 2012.

[2] L. Xian-peng, "Research on the establishment of the statistical indicators of sport industry in china," China Sport Sci., vol. 20, no. 4, pp. 1-5, 2000.

[3] L. Lei, Z. Lin, and H. Hai-yan, "Commentary of researches on sports industry in china during 30-year reform and opening," China Sport Sci., vol. 32, no. 11, pp. 83-89, 2012.

[4] M. Xiao-bing, and L. Xiang, "Rational layout of sports industry in sichuan province," J. Chengdu Phys. Educ. Inst., vol. 38, no. 9, pp. 12-15, 2012.

[5] Z. Li, W. Li-yuan, X. Xiao-juan, and L. Chang, "Sports industry statistics and construction of related systems in our country," $J$. Shanghai Phys. Educ. Inst., vol. 31, no.1, pp. 38-43, 2007. 